Check for updates

Cite this: RSC Adv., 2017, 7, 54021

Received 16th October 2017 Accepted 19th November 2017

DOI: 10.1039/c7ra11437k

rsc.li/rsc-advances

\section{Simultaneous enhancements in the mechanical, thermal stability, and flame retardant properties of poly(1,4-butylene terephthalate) nanocomposites with a novel phosphorus-nitrogen-containing polyhedral oligomeric silsesquioxane $\dagger$}

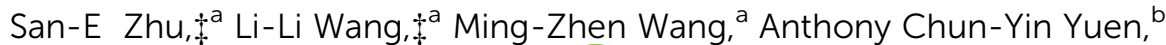 \\ Timothy Bo-Yuan Chen, ${ }^{\text {b }}$ Wei Yang, (D) *ab Tian-Zhu Pan, ${ }^{a}$ You-Ran Zhi ${ }^{c}$ \\ and Hong-Dian Lu*a
}

\begin{abstract}
Highly efficient flame retardants for engineering plastics are needed to reduce the deterioration of the mechanical and other properties of the host polymer. Herein, a novel functionalized polyhedral oligomeric silsesquioxane (F-POSS) containing phosphorus and nitrogen has been synthesized by the reaction between $\mathrm{N}$-phenylaminopropyl-POSS and diphenylphosphinic chloride. Untreated POSS and FPOSS have been respectively mixed with poly(1,4-butylene terephthalate) (PBT) to prepare the nanocomposites via the melt blending method. PBT/F-POSS shows improved mechanical properties, thermal stability and thermo-oxidative resistance in comparison with PBT/POSS. F-POSS exhibits a more significant inhibiting effect on the smoke production of PBT in the early heating stage of smoke density testing without a flame. In cone calorimeter tests, the peak heat release rate (PHRR), peak smoke production rate (PSPR), peak carbon dioxide production $\left(\mathrm{PCO}_{2} \mathrm{P}\right)$ and peak carbon monoxide production (PCOP) of PBT/F-POSS are reduced by $50 \%, 46 \%, 45 \%$ and $35 \%$, respectively, compared to those of neat PBT. Residue analysis indicates that more $C$ and $O$ elements are left during the expansion and carbonization process in which phosphinic groups of F-POSS can capture the free radicals or decomposed products produced from PBT to form a stable $\mathrm{SiO}_{x} \mathrm{C}_{y} \mathrm{P}_{z}$ network. The multiple protective char layers act as a thermal barrier at the surface of the substrate to reduce the fire, smoke and toxicity hazards. This work provides a facile and simple way to achieve high-performance PBT nanocomposites.
\end{abstract}

\section{Introduction}

The demand for various polymers applied in infrastructure construction, civil facilities, and other engineering and technology fields is increasing annually with population growth and economic development. Engineering plastics exhibit superior heat resistance, mechanical strength, rigidity and chemical stability, and hence they are widely applied in construction, automobiles, electronic devices and offshore structures. Poly(1,4-butylene terephthalate) (PBT) is a typical engineering

\footnotetext{
${ }^{a}$ Department of Chemical and Materials Engineering, Hefei University, 99 Jinxiu Avenue, Hefei, Anhui, 230601, People's Republic of China. E-mail: luhdo@hfuu.edu. cn; yangwei@hfuu.edu.cn; Tel: +86-551-62158393; +86-551-62158394

${ }^{b}$ School of Mechanical and Manufacturing Engineering, University of New South Wales, Sydney, NSW 2052, Australia

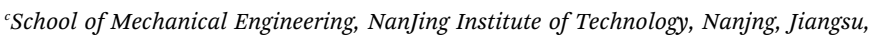
People's Republic of China

$\dagger$ Electronic supplementary information (ESI) available. See DOI: $10.1039 / \mathrm{c} 7 \mathrm{ra} 11437 \mathrm{k}$

¥ These authors contributed equally to this work (co-first author).
}

plastic particularly used in the electrical and electronics industries..$^{1-4}$ The insulated enclosures fabricated based on PBT resins without flame retardant treatment is ignited easily by electric spark, short circuit, and other leakage accidents. The ignitability of PBT-based insulating materials leads to flame propagation, heat radiation, smoke production and serious dripping. The generation of thermal and non-thermal hazards in fire accidents impairs the evacuation of building occupants and the rescue operations of fire brigades resulting in injuries and fatalities.

Flame-retardant systems most commonly used in PBT are composed of halogen-containing additives and antimony trioxide. Unfortunately, most of halogenated compounds are gradually banned in many countries resulting from the adverse effects to human health and environment due to the toxicity and corrosive nature of the pyrolytic halogenated species. Recently, aluminium phosphinate and aluminium hypophosphite with similar molecular structure and relatively high oxidation state of $\mathrm{P}$ atom have proven to be particularly effective in PBT. ${ }^{5-9}$ They play a dominant role of gas-phase action leading 
to flame inhibition. Although the condensed-phase residues composed of aluminium phosphates and few carbon char are induced, they are not able to serve as an efficient insulating barrier to reduce the exposure of polymer matrix to an external heat source and as well inhibit the flammable gases from feeding the flame.

Plenty of research achievements have demonstrated that nano-additives, including nanoclay, carbon nanotubes, graphene, layered double hydroxides, graphitic carbon nitride, hexagonal boron nitride, and polyhedral oligomeric silsesquioxanes (POSS), can significantly reduce the flammability properties of polymers with the addition of very small loadings. ${ }^{2,8,10-16}$ Only few nano-additives, e.g. nano-clay, ${ }^{2,8,17,18}$ and graphene $^{19}$ have been explored to improve the flame retardancy of PBT, as well as other properties. In comparison with the other nanoparticles, POSS has a unique advantage of organic-inorganic hybrids with nanoscale three-dimensional, cage-shaped structure that can be homogeneously incorporated into almost all kinds of thermoplastic or thermoset polymers through facile processing methods. ${ }^{\mathbf{1 6 0 - 2 2}}$ Cubic octamer POSS has a general molecular formula $\left(\mathrm{RSiO}_{1.5}\right)_{8}$ composed of a welldefined silica-like inorganic core surrounded by eight organic groups, such as alkyl, aryl, epoxy group, and organo-functional derivatives. ${ }^{20-22}$ A variety of reactive peripheral groups in POSS can be particularly grafted with many functional organics, to improve the mechanical and thermal properties as well as flame retardancy of polymer nanocomposites..$^{16,20,22-27}$ POSS reacted with phosphorus-based compounds is regarded as an effective and facile method to improve the inherent flame retardant properties. Phosphorus-containing POSS nanoparticles or clusters with relatively high oxidation state of phosphorus have been effective for reducing the flammability of polycarbonate and epoxy resins (ERs) in terms of rapid swelling, accumulation of pyrolysis gases in the condensed phase, and fast charring. ${ }^{16,20,26,27}$ Zhang et al. ${ }^{16}$ prepared a 9,10-dihydro-9-oxa-10phosphaphenanthrene-10-oxide based POSS (DOPO-POSS) which remarkably reduced the fire hazards of ERs through a blowing-out extinguishing effect. Qi et al. ${ }^{27}$ investigated the fire retardant efficiency of three phosphorus-containing POSSs with different oxidation states of $\mathrm{P}$ atom on ER. They found that the addition of P-based POSS with lower oxidation state could form more $\mathrm{C}$ and $\mathrm{O}$ elements in the chars through the synergistic effect between phosphorus and silicon.

In order to further improve the flame retardant efficiency of functionalized POSS, a phosphorus-nitrogen-containing POSS with low oxidation state of phosphorus was designed and synthesized in the current work. Diphenylphosphinic chloride (DPP-Cl) was reacted with $N$-phenylaminopropyl-POSS to prepare a novel phosphorus-nitrogen-containing POSS, which was then incorporated into PBT to prepare nanocomposites through a melt blending method. The objective of this work was to study the effect of the novel POSS on the mechanical, thermal stability, and flame retardant properties of PBT by means of universal testing machine, thermogravimetric analysis (TGA), cone calorimeter, and smoke density chamber. Furthermore, to reveal how the structure of char influences the suppression properties of fire, smoke, and toxicity hazards, the nanocomposite residues collected after cone calorimeter testing were studied by scanning electron microscopy (SEM) coupled with energy dispersive X-ray (EDX) analyzer.

\section{Experimental}

\section{Materials}

Poly(1,4-butylene terephthalate) (PBT, B4500) was provided by BASF Chemical Company, Germany. $N$-PhenylaminopropylPOSS (NPAP-POSS, AM0281) with a molecular formula $\left(\mathrm{C}_{9^{-}}\right.$ $\left.\mathrm{H}_{12} \mathrm{~N}\right)_{n}\left(\mathrm{SiO}_{1.5}\right)_{n}(n=8,10$ and 12$)$ was obtained from Hybrid Plastics $^{\mathrm{TM}}$. The structure of NPAP-POSS was illustrated in Fig. 1. Diphenylphosphinic chloride (DPP-Cl, 98\%), triethylamine (TEA, 99.5\%), and tetrahydrofuran (THF, 99.9\%) were all obtained from the Aladdin Reagent Co. Ltd., China. THF and TEA were dried over $0.4 \mathrm{~nm}$ molecular sieves before use. Other reagents were used as-received without further purification.

\section{Synthesis of phosphorus-nitrogen-containing functionalized POSS}

The reaction process for phosphorus-nitrogen-containing functionalized POSS is illustrated in Fig. 1. NPAP-POSS $(1.49 \mathrm{~g}, 1.0 \mathrm{mmol})$ and TEA $(0.81 \mathrm{~g}, 8.0 \mathrm{mmol})$ were dissolved in dry THF $(100 \mathrm{~mL})$ in a three-neck flask cooled in an ice bath under dry nitrogen condition. DPP-Cl (1.89 g, $8.0 \mathrm{mmol})$ dissolved in dry THF $(20 \mathrm{~mL})$ was placed in a constant pressure dropping funnel and then added dropwise into the mixed solution. The solution was stirred with a magnetic stirrer in an ice-water bath for $1 \mathrm{~h}$ under dry nitrogen condition, and then kept at room temperature for $12 \mathrm{~h}$. When the reaction completed, the solvent was removed through a rotary evaporator. The residual solid was dissolved in ethyl acetate (EA) and washed using saturated $\mathrm{NaHCO}_{3}$ solution for three times. The organic phase was dried over anhydrous magnesium sulfate and concentrated via a rotary evaporator. The residue was purified chromatographically $\left(\mathrm{EA}-\mathrm{CH}_{2} \mathrm{Cl}_{2}, 1: 3\right)$. The phosphorus, nitrogen and silicon contents are $8.03 \mathrm{wt} \%, 3.62 \mathrm{wt} \%$ and $7.25 \mathrm{wt} \%$, respectively. The final product $N$-diphenylphosphoryl- $N$-phenylaminopropyl POSS was abbreviated as functionalized-POSS (F-POSS), and NPAP-POSS was designated as POSS in this study.

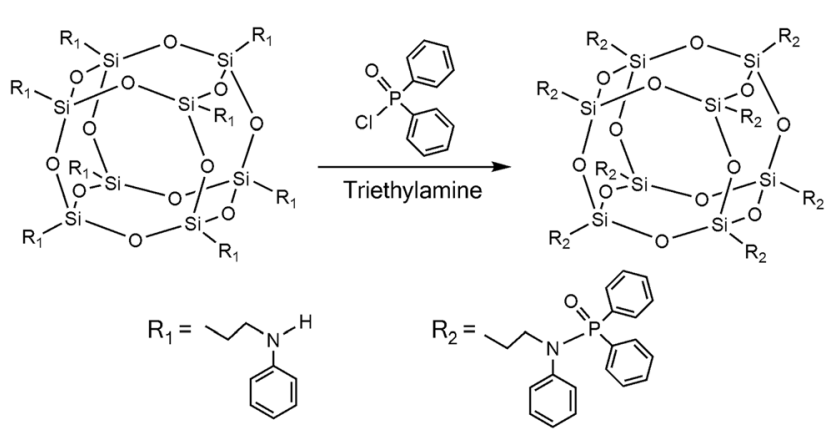

Fig. 1 Schematic representation of the synthesis route for F-POSS. 


\section{Preparation of PBT/functionalized POSS nanocomposites}

PBT, POSS, and F-POSS were continuously dried at $80{ }^{\circ} \mathrm{C}$ for $12 \mathrm{~h}$. In a typical melt blending experiment, $2.5 \mathrm{~g}$ of POSS or FPOSS was blended with $47.5 \mathrm{~g}$ of PBT to prepare the nanocomposites using a XK-160 twin-roll mill (Jiangsu, China) at $235{ }^{\circ} \mathrm{C}$ under a constant rotation speed of $100 \mathrm{rpm}$ for approximately $10 \mathrm{~min}$. Subsequently, the mixtures were then molded through a hot press at $245{ }^{\circ} \mathrm{C}$ to obtain the samples for further measurements. The prepared nanocomposites in this work were designated as PBT/POSS and PBT/F-POSS with the same concentration (5 $\mathrm{wt} \%)$.

\section{Characterizations and measurements}

The microstructure and chemical composition of F-POSS were characterized by nuclear magnetic resonance (NMR) and Fourier transform infrared spectroscopy (FTIR). ${ }^{1} \mathrm{H}-$ and ${ }^{31} \mathrm{P}-\mathrm{NMR}$ spectra were recorded on a Bruker Avance NMR spectrometer (400 MHz). $\mathrm{CDCl}_{3}$ was used as the solvent. FTIR spectra were recorded on a FTIR spectrophotometer (Nicolet 6700). Thermal decomposition behaviors were performed on a Q5000 IR TGA (TA Instruments). The specimens were heated from $25{ }^{\circ} \mathrm{C}$ to $700{ }^{\circ} \mathrm{C}$ at a rate of $20{ }^{\circ} \mathrm{C}$ min in $\mathrm{N}_{2}$ atmosphere.

Tensile properties of neat PBT and its nanocomposites were evaluated by a WD-20D universal testing machine according to the standard ASTM D-638. The width and thickness of specimens were $4.0 \pm 0.1 \mathrm{~mm}$ and $2.0 \pm 0.1 \mathrm{~mm}$, respectively. The crosshead speed was set as $20 \mathrm{~mm} \mathrm{~min}^{-1}$. Five runs for each sample were measured, and the average value was reported.

Thermal decomposition and thermo-oxidative degradation behaviors of neat PBT and its nanocomposites were performed on a Q5000 IR TGA (TA Instruments). The specimens were heated from $25{ }^{\circ} \mathrm{C}$ to $700{ }^{\circ} \mathrm{C}$ at a rate of $20{ }^{\circ} \mathrm{C}$ min in $\mathrm{N}_{2}$ or air atmosphere. The sample mass was in the range of 5-10 mg.

The flame retardant properties of neat PBT and its nanocomposites were studied using a FTT cone calorimeter (UK) on the basis of the standard ISO 5660-1. The sample size was $100 \times$ $100 \times 3.0 \mathrm{~mm}^{3}$. All samples were wrapped by a layer of aluminum foil. They were then horizontally irradiated under a heat flux of $50 \mathrm{~kW} \mathrm{~m}{ }^{-2}$. Smoke evolution properties of neat PBT and its nanocomposites were determined by a smoke density chamber (JQMY-2, Jianqiao Co., China) complying with NBS specifications under smoldering conditions. This experiment was performed according to the ISO 5659-2 (2006). Each specimen with dimensions of $75 \times 75 \times 3.0 \mathrm{~mm}^{3}$ were wrapped in aluminum foil and exposed horizontally to an external heat flux of $25 \mathrm{~kW} \mathrm{~m}{ }^{-2}$ without a pilot flame.

Some residues collected in the cone calorimeter tests were analyzed by means of the SEM coupled with an EDX analyzer. The SEM micrographs were obtained with a Hitachi SU8010 SEM (Japan) at an accelerating voltage of $10 \mathrm{kV}$. The specimens were sputter-coated with a conductive layer. The surface elements achieved from EDX were performed on an EMAX energy spectroscopy (HORIBA, Ltd., Japan).

\section{Results and discussion}

\section{Characterizations of POSS and F-POSS}

The ${ }^{1} \mathrm{H}-\mathrm{NMR}$ spectra of POSS and F-POSS are shown in Fig. 2(a). In the spectrum of POSS, the signals at 0.57-0.81 ppm $\left(\mathrm{H}_{\mathrm{a}}\right)$, 1.58-1.80 ppm $\left(\mathrm{H}_{\mathrm{b}}\right)$, and 2.91-3.20 $\mathrm{ppm}\left(\mathrm{H}_{\mathrm{c}}\right)$ correspond to $\mathrm{H}$ atoms of $-\mathrm{Si}-\mathrm{CH}_{2}-,-\mathrm{CH}_{2}-$, and $-\mathrm{CH}_{2}-\mathrm{NH}-$ groups between $\mathrm{Si}$ and $\mathrm{N}$ atoms, respectively. The broad peak at $3.55 \mathrm{ppm}\left(\mathrm{H}_{\mathrm{d}}\right)$ is ascribed to the secondary amino proton of POSS. ${ }^{28}$ The signals at 6.45-6.67 $\left(\mathrm{H}_{\mathrm{g}}\right)$, 6.69-6.85 $\left(\mathrm{H}_{\mathrm{f}}\right)$ and 7.11-7.34 $\left(\mathrm{H}_{\mathrm{e}}\right)$ ppm are attributed to $\mathrm{H}$ atoms of the benzene ring. For the spectrum of F-POSS, the broadened peak at 3.55 ppm disappears. The signals at 0.48-0.79 ppm $\left(\mathrm{H}_{\mathrm{a}}\right), 1.54-1.81 \mathrm{ppm}\left(\mathrm{H}_{\mathrm{b}}\right)$, and 2.85$3.18 \mathrm{ppm}\left(\mathrm{H}_{\mathrm{c}}\right)$ are ascribed to $\mathrm{H}$ atoms of $-\mathrm{Si}-\mathrm{CH}_{2}-,-\mathrm{CH}_{2}-$, and $-\mathrm{CH}_{2}-\mathrm{NH}$ - groups between $\mathrm{Si}$ and $\mathrm{N}$ atoms, respectively. The signals at 6.47-6.67 ppm $\left(\mathrm{H}_{\mathrm{g}}\right), 6.68-6.83 \mathrm{ppm}\left(\mathrm{H}_{\mathrm{f}}\right)$ and 7.05$7.22 \mathrm{ppm}\left(\mathrm{H}_{\mathrm{e}}\right)$ are attributed to $\mathrm{H}$ atoms of the benzene ring, which is covalently bonded with $\mathrm{N}$ atom. These lower chemical shifts are assigned to the negative induction effect of $\mathrm{P}=\mathrm{O}$ double bond. The new signals at 7.22-7.33 ppm $\left(\mathrm{H}_{\mathrm{j}}\right)$, 7.34$7.45 \mathrm{ppm}\left(\mathrm{H}_{\mathrm{i}}\right)$ and 7.71-7.93 ppm $\left(\mathrm{H}_{\mathrm{h}}\right)$ are attributed to $\mathrm{H}$ atoms of the benzene ring, which is covalently bonded with $\mathrm{P}$ atom. These chemical shifts are respectively lower than those in DPP$\mathrm{Cl}$ (Fig. S1 $\dagger$ ), because of the negative induction effect of amino group.

The ${ }^{31} \mathrm{P}-\mathrm{NMR}$ spectra of DPP-Cl and F-POSS are shown in Fig. 2(b). The ${ }^{31} \mathrm{P}-\mathrm{NMR}$ spectrum of DPP-Cl shows a strong and sharp peak at $44.8 \mathrm{ppm}$ which shifts to $21.2 \mathrm{ppm}$ for F-POSS, because the electronegativity of $\mathrm{Cl}$ atom is higher than that of $\mathrm{N}$ atom. These results indicate that the $\mathrm{Cl}$ atom in $\mathrm{P}-\mathrm{Cl}$ group is replaced by $\mathrm{N}$ atom of POSS in nucleophilic-substitution reaction.

The FTIR spectra of POSS and F-POSS are shown in Fig. 2(c). In the FTIR spectrum of POSS, the absorption band at $3410 \mathrm{~cm}^{-1}$ is attributed to the $\mathrm{N}-\mathrm{H}$ stretching vibration..$^{29,30}$ The bands at 2802-2995 $\mathrm{cm}^{-1}$ and $1350-1472 \mathrm{~cm}^{-1}$ represented by gray area in Fig. 2(c) are assigned to the $\mathrm{C}-\mathrm{H}$ stretching and bending vibration in methylene groups, respectively. The strong absorption band at $1097 \mathrm{~cm}^{-1}$ corresponds to Si-O-C stretching vibration. ${ }^{31}$ In the FTIR spectrum of F-POSS, the absorption band at $3410 \mathrm{~cm}^{-1}$ becomes weak. The bands at 3025 and $798 \mathrm{~cm}^{-1}$ correspond to the $\mathrm{C}-\mathrm{H}$ stretching and bending vibration of the benzene ring, respectively. In addition, the peaks at 1504 and $1601 \mathrm{~cm}^{-1}$ are ascribed to the $\mathrm{C}=\mathrm{C}$ stretching vibration of the benzene ring. The new peaks at 1250 and $1023 \mathrm{~cm}^{-1}$ respectively correspond to $\mathrm{P}=\mathrm{O}$ and $\mathrm{P}-\mathrm{N}$ stretching vibration..$^{27,32-34}$ The appearance of $\mathrm{P}=\mathrm{O}$ and $\mathrm{P}-\mathrm{N}$ absorption bands in combination with the reduction of $\mathrm{N}-\mathrm{H}$ absorption band show that the $\mathrm{Cl}$ atom in DPP-Cl is replaced by $\mathrm{N}$ atom of POSS in nucleophilic-substitution reaction with the elimination of $\mathrm{HCl}$. Based on the ${ }^{1} \mathrm{H}-\mathrm{NMR},{ }^{31} \mathrm{P}-\mathrm{NMR}$, and FTIR analysis results, it can be concluded that F-POSS has been successfully synthesized.

The thermal decomposition behaviors of POSS and F-POSS under nitrogen condition are presented in Fig. 2(d). The thermal decomposition of POSS begins at $397{ }^{\circ} \mathrm{C}\left(T_{-5 \%}\right)$ with 

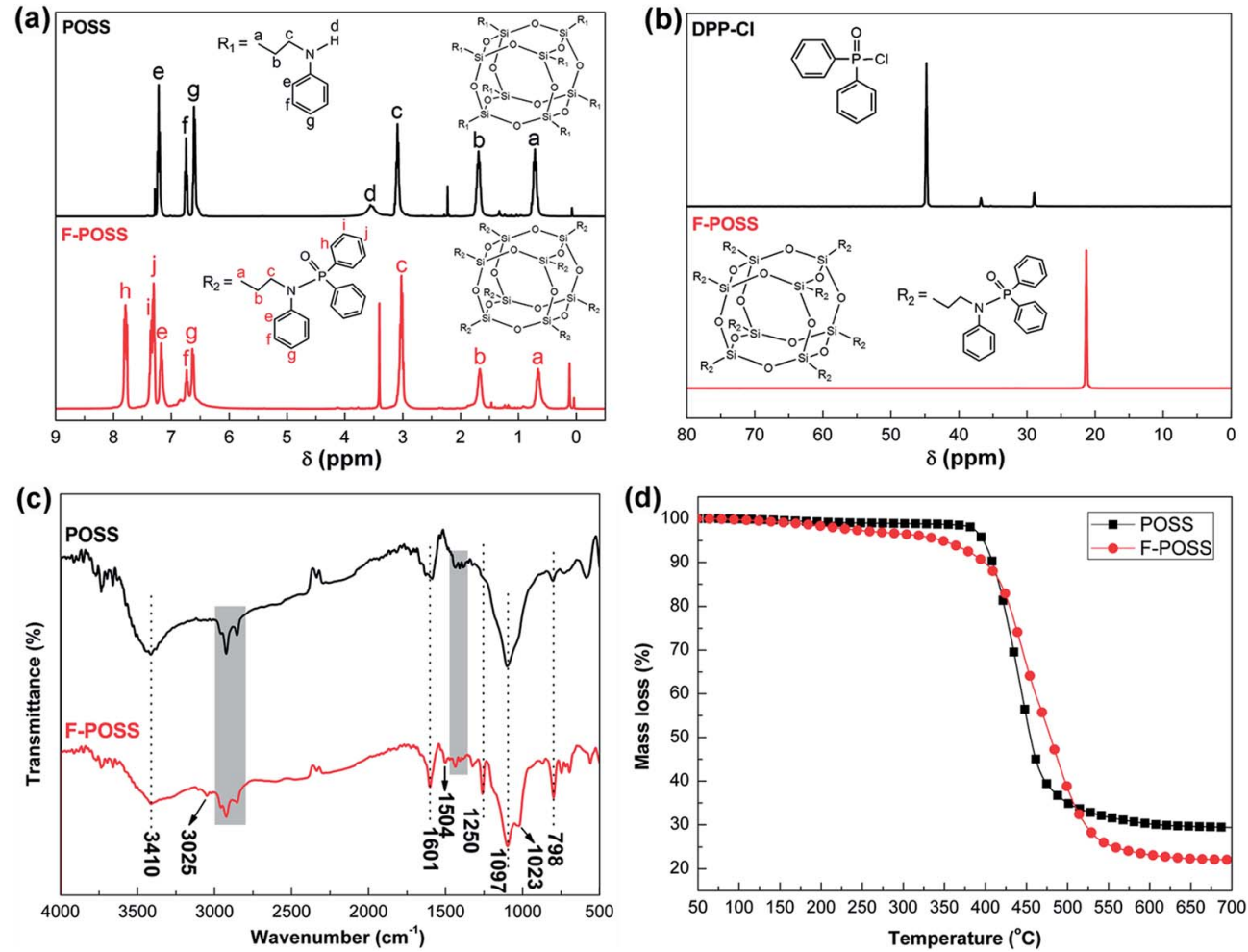

Fig. 2 Characterizations of POSS and F-POSS: (a) ${ }^{1} \mathrm{H}$-NMR spectra; (b)

${ }^{31} \mathrm{P}$-NMR spectra; (c) FTIR spectra; (d) thermal decomposition curves.

a $29.4 \mathrm{wt} \%$ residue left at $700{ }^{\circ} \mathrm{C}$. The good thermal stability of POSS shows that the peripheral organic groups in POSS are thermally stable. The pyrolytic decomposition to the partial loss of the organic substituents of POSS follows by the formation of $\mathrm{SiO}_{x} \mathrm{C}_{y}$ networks in the final residue. ${ }^{35,36}$ The $T_{-5 \%}$ value of $\mathrm{F}$ POSS is $347^{\circ} \mathrm{C}$. The reduced thermal decomposition temperature may be attributed to the introduction of the phosphoryl groups. The final weight of F-POSS at $700{ }^{\circ} \mathrm{C}$ is $22.1 \%$, which is lower than that of POSS. This indicates that the diphenylphosphinic groups are grafted in POSS. The increasing organic groups in F-POSS lead to a mass loss during the thermal decomposition process.

\section{Mechanical properties}

The mechanical properties of neat PBT and its nanocomposites were studied through their tensile properties, as shown in Fig. 3. The corresponding data are summarized in Table S1. $\dagger$ From the stress-strain curves (Fig. 3), it is observed that both the incorporation of POSS and F-POSS nanoparticles into PBT enhance the tensile strength at the expense of the elongation at break. PBT/F-POSS shows a $12 \%$ increase in tensile strength of 55.6 MPa relative to neat PBT. The improved tensile properties of PBT/F-POSS nanocomposites is attributed to the better dispersion of F-POSS in PBT matrix compared to POSS. Morphological analysis (seeing in ESI $\dagger$ ) reveals that F-POSS is evenly dispersed in PBT, which is favorable to the load transfer from PBT matrix to the hard inorganic core of F-POSS nanoparticles. As shown in Fig. 3 and Table S1, $\uparrow$ the elongation at break values for the PBT nanocomposites decrease with the introduction of POSS and F-POSS nanoparticles (neat PBT > PBT/POSS > PBT/F-POSS), whiles the tensile strength values show an inverse trend. PBT nanocomposites become brittle in comparison with neat PBT, because of the increased stiffness of the PBT nanocomposites. On the other hand, the continuity of PBT matrix is destroyed due to the presence of POSS and F-POSS nanoparticles. As a result, the elongation at break values of PBT/ POSS and PBT/F-POSS are reduced.

\section{Thermal decomposition behaviors}

The thermal decomposition behaviors of neat PBT and its nanocomposites are presented in Fig. 4, and the corresponding

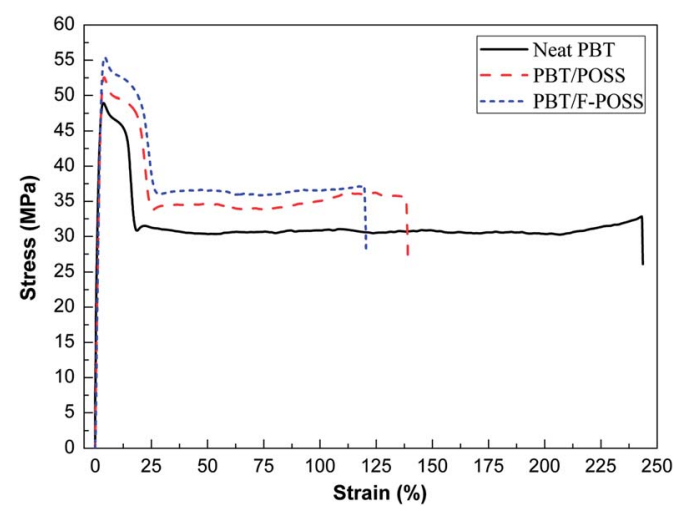

Fig. 3 Tensile stress-strain curves of neat PBT, PBT/POSS, and PBT/FPOSS. 

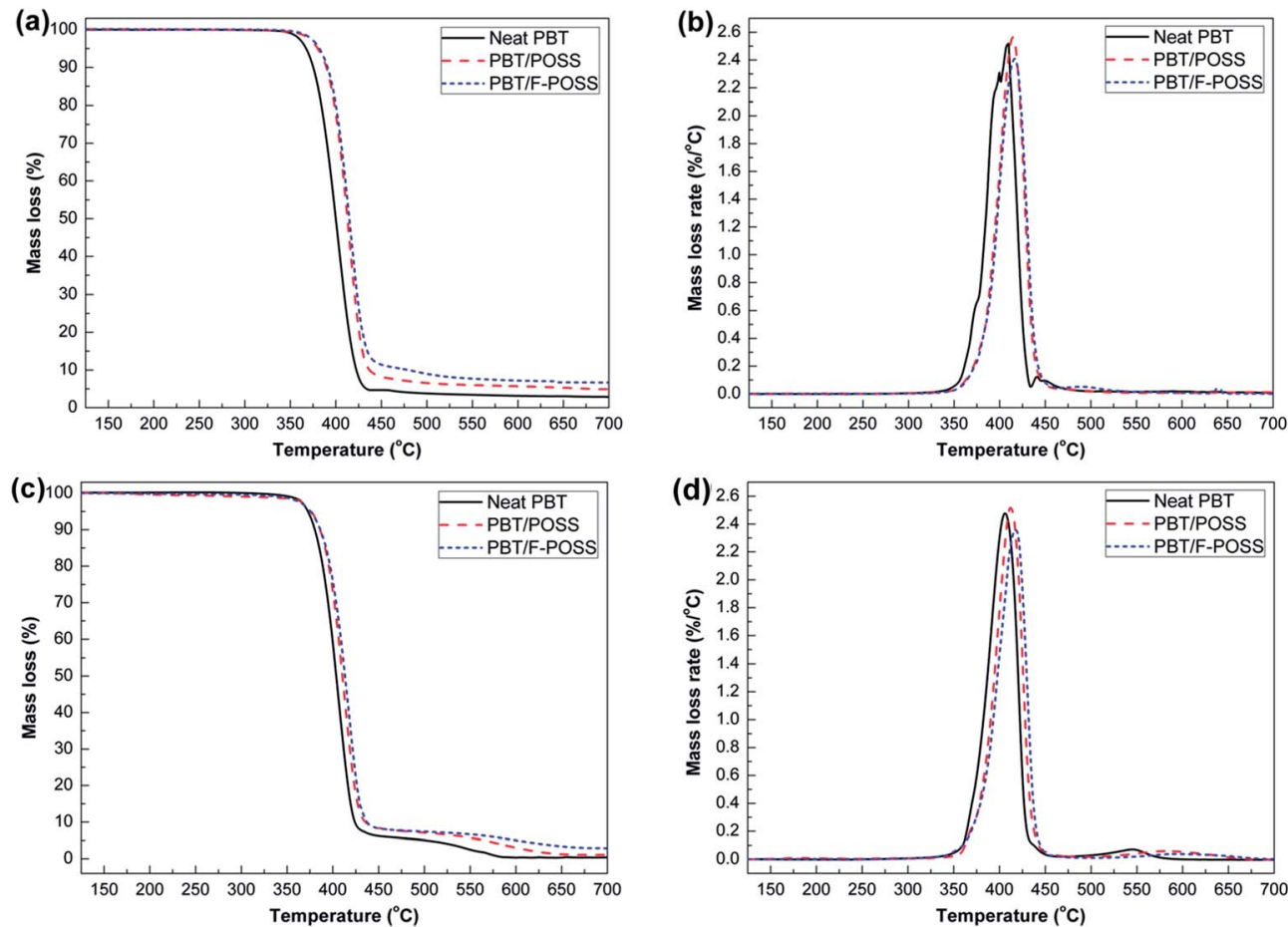

Fig. 4 Mass loss and mass loss rate curves of neat PBT, PBT/POSS and PBT/F-POSS: (a and b) under nitrogen condition; (c and d) under air condition.

data are listed in Table S2. $\dagger$ From Fig. 4(a), it can be seen that the thermal degradation behavior of each sample exhibits a single stage decomposition under nitrogen atmosphere. In the case of neat PBT, more than $97 \%$ mass loss occurred with a meagre $2.7 \mathrm{wt} \%$ residue left at $700{ }^{\circ} \mathrm{C}$. During the thermal degradation, the main volatiles, including butadiene, carbon dioxide, tetrahydrofuran, benzoic acid and ester derivatives, are released, leaving a few solid residues with acidic and anhydride structures. ${ }^{6}$ The incorporation of POSS and F-POSS lead to the improvement in thermal stability and char yields of PBT and a more significant effect is observed for the PBT/F-POSS composite. For example, the $T_{-5 \%}$ value increases from $367{ }^{\circ} \mathrm{C}$ for virgin PBT to $380{ }^{\circ} \mathrm{C}$ and $382{ }^{\circ} \mathrm{C}$ respectively for PBT/POSS and PBT/F-POSS. The $T_{\max }$ value improves from $408{ }^{\circ} \mathrm{C}$ for neat PBT to $414{ }^{\circ} \mathrm{C}$ and $416{ }^{\circ} \mathrm{C}$ respectively for PBT/POSS and PBT/F-POSS. Because of the good thermal stability and the cagelike structure of POSS nanoparticles, the inorganic POSS $\left(\mathrm{RSiO}_{1.5}\right)_{n}$ delays the flame propagation and heat transfer along the nanocages. ${ }^{37,38}$ As a result, the thermal stability of PBT is improved significantly by the introduction of POSS and F-POSS. PBT/F-POSS has a high residual weight (6.7 wt\%), more than that of PBT/POSS (4.9 wt\%), as shown in Fig. 4(a) and Table S2. $\dagger$ The improved residue yield of PBT/POSS is attributed to the $\mathrm{SiO}_{x} \mathrm{C}_{y}$ solid residue decomposed from POSS. The higher residual weight of $\mathrm{PBT} / \mathrm{F}$-POSS implies that the incorporating functionalized POSS with phosphinic groups effectively promotes the char formation. From Fig. 4(b), it is observed that the addition of POSS increases the maximum mass loss rates (MMLR) slightly. On the contrary, the incorporation of F-POSS decreases the MMLR value. This phenomenon indicates that
F-POSS could participate and accelerate the cross-linking reaction of the decomposed products formed in the condensed phase, which is beneficial to enhancing the strength and thermal stability of the char layer. ${ }^{26,27}$ Additionally, the good dispersion of F-POSS in PBT matrix can effectively retard the thermal decomposition of PBT macromolecular chains, resulting in further enhancement in the thermal stability and residue yields of PBT/F-POSS.

\section{Thermo-oxidative degradation behaviors}

The thermo-oxidative degradation behaviors of virgin PBT and its nanocomposites was measured by TGA under air condition. Fig. 4(c and d) shows the thermo-oxidative degradation curves of each sample. The corresponding data are also listed in Table S2. $\uparrow$ The thermo-oxidative degradation behaviors of PBT and its nanocomposites are different from their thermal decomposition curves in nitrogen atmosphere. All the degradation behaviors of neat PBT and its nanocomposites are characterized by two steps: PBT chains decompose and initial residues are formed in the first step; the second step is attributed to the slow oxidation degradation of the unstable residues. ${ }^{39,40}$ For the firststep degradation, the $92 \%$ mass loss in the temperature range of $350-430{ }^{\circ} \mathrm{C}$ is attributed to the release of benzoic acid, butadiene, anhydrides, alcohols, carbon dioxide, ester derivates, aromatic and aliphatic acids. ${ }^{39,40}$ The mass loss in the first step is not greatly influenced by the introduction of POSS and F-POSS based on similar degradation curve and initial decomposition temperature $\left(T_{-5 \%}\right)$. However, the addition of POSS or F-POSS promotes an increase in the degradation temperature in 
the range of $440-600{ }^{\circ} \mathrm{C}$. For example, the $T_{\max }$ values of the nanocomposites shift to higher temperatures when POSS or F-POSS are added $\left(\Delta T_{\max 1}=+6,+12{ }^{\circ} \mathrm{C}\right.$; and $\Delta T_{\max 2}=+26$, $+53{ }^{\circ} \mathrm{C}$ ). This increase is probably attributed to the portions of the structure in the inorganic core of POSS, which can promote a delay in heat transfer along the nanocages. ${ }^{37,38}$ In the range of 500-700 ${ }^{\circ} \mathrm{C}$, the residue yields for the nanocomposites are increased. PBT/F-POSS exhibits much slower thermo-oxidative degradation behavior and higher residue yields in the high temperature region. Additionally, the MLR curve of PBT/F-POSS shows lower MMLR values at both degradation stages in Fig. 4(d), indicating the better oxidation resistance. In the reported study, ${ }^{27}$ P-based POSS with lower oxidation state can maintain more $\mathrm{C}$ and $\mathrm{O}$ elements in the carbonization process. In the current work, the phosphinic groups in F-POSS reacts with oxygen to form phosphate derivatives, which can catalyze decomposed products of PBT carbonization to produce stable char layers which act as a physical barrier to reduce the amount of oxygen available for the oxidation of underlying carbon char, resulting in the improved oxidation resistance in high temperature region.

\section{Flame retardant properties}

Flame retardant properties of PBT and its nanocomposites were investigated by cone calorimeter under a forced combustion. The fire, toxicity, and smoke hazard parameters, including heat release rate (HRR), total heat release (THR), CO production (COP), $\mathrm{CO}_{2}$ production $\left(\mathrm{CO}_{2} \mathrm{P}\right)$, smoke production rate (SPR), and total smoke production (TSP) were obtained from cone calorimeter tests at a heat flux of $50 \mathrm{~kW} \mathrm{~m}^{-2}$. The HRR and THR curves of neat PBT and its nanocomposites are shown in Fig. 5(a and b). The related data are summarized in Table S3. $\uparrow$ Neat PBT burns at $52 \mathrm{~s}\left(t_{\text {ign }}\right.$ value) with a high PHRR value $\left(1104 \mathrm{~kW} \mathrm{~m}^{-2}\right)$, and a HRR-peak appears at $150 \mathrm{~s}\left(t_{\mathrm{p}}\right.$ value). Although the incorporation of POSS into PBT improves the $t_{\text {ign }}$ and $t_{\mathrm{p}}$ values $\left(\Delta t_{\text {ign }}=\right.$ $+15 \mathrm{~s} ; \Delta t_{\mathrm{p}}=+30 \mathrm{~s}$ ), the effect on HRR curves is limited. The HRR shape of PBT/POSS is similar to that of neat PBT as well as the PHRR and THR values. The delayed $t_{\text {ign }}$ and $t_{\mathrm{p}}$ are attributed to the ceramization process involving polysilsesquioxanes migration on the surface to inhibit the heat radiation and mass transfer in the early stage of forced combustion. ${ }^{41}$ The continuously elevated temperature results in the destruction of protective ceramic layer. The rate of mass loss is accelerated leading to the increased HRR. The introduction of F-POSS into PBT also brings an increase in $t_{\text {ign }}$ compared to neat PBT $\left(\Delta t_{\text {ign }}=+8 \mathrm{~s}\right)$. After ignition, the HRR increases rapidly with a significant reduction in flame propagation leading to a flat peak from $175 \mathrm{~s}$ to $200 \mathrm{~s}$. It reaches to the peak at $210 \mathrm{~s}\left(\Delta t_{\mathrm{p}}=+60 \mathrm{~s}\right)$. PHRR decreases from $1104 \mathrm{~kW} \mathrm{~m}^{-2}$ for pure PBT to $556 \mathrm{~kW} \mathrm{~m}^{-2}$ for PBT/F-POSS with a significant reduction of $c a$. $50 \%$. From Fig. 5(b) and Table S3, $\dagger$ it is seen that PBT/F-POSS has the lowest THR, which is reduced from $65.2 \mathrm{MJ} \mathrm{m}^{-2}$ for pure PBT to $62.7 \mathrm{MJ}$ $\mathrm{m}^{-2}$ with a reduction of $c a .4 \%$. The results show that the introduction of F-POSS inhibits the heat release rate through rapid swelling, capture effect of phosphoric radicals and phosphorus-nitrogen-silicon ternary synergistic effect. ${ }^{\mathbf{4 2 - 4 4}}$
In the toxic gases produced from the burning polymers, $\mathrm{CO}_{2}$ and $\mathrm{CO}$ are the main culprit represented by their asphyxiant for the fatality in a real fire. The $\mathrm{CO}_{2}$ and $\mathrm{CO}$ production profiles of virgin PBT and its nanocomposites are showed in Fig. 5(c and d). The corresponding parameters are listed in Table S3. $\dagger$ In the $\mathrm{CO}_{2} \mathrm{P}$ and COP curves of neat PBT, both $\mathrm{CO}_{2}$ and $\mathrm{CO}$ emitted from samples increase significantly after the ignition at $52 \mathrm{~s}$, because the $\mathrm{CO}_{2}, \mathrm{CO}$, and smoke increase as flames appear on materials. ${ }^{45}$ The introduction of POSS delays the $\mathrm{PCO}_{2} \mathrm{P}$ and PCOP, but the peak values are not fundamentally affected. The incorporation of F-POSS further delays the $\mathrm{PCO}_{2} \mathrm{P}$ and PCOP as well as ensuring a significant reduction in $\mathrm{PCO}_{2} \mathrm{P}$ and PCOP values of PBT. In comparison with neat $\mathrm{PBT}$, the $\mathrm{PCO}_{2} \mathrm{P}$ and PCOP values for PBT/F-POSS are reduced by nearly $45 \%$ and $35 \%$, respectively. It indicates that the incorporation of F-POSS remarkably inhibits the release of $\mathrm{CO}_{2}$ and $\mathrm{CO}$. The significant reduction of $\mathrm{CO}_{2}$ and $\mathrm{CO}$ contributes to the dilution of flammable gases and the reduction of toxic volatile products in the flaming process, which is quite beneficial for fire safety. ${ }^{\mathbf{1 2 , 4 6 , 4 7}}$ The possible flame retardant mechanism will be discussed in the next section according to residue analysis.

Smoke and smoke particulates produced in a real fire is the primary obstacle for personnel evacuation. ${ }^{\mathbf{1 5 , 4 8}}$ The reduction of the smoke production during burning is quite important to extend the time for evacuating and rescuing. In order to evaluate the smoke evolution properties of PBT and its nanocomposites, cone calorimeter and smoke density chamber tests were performed. Fig. 5(e and f) respectively shows the SPR and TSP curves of neat PBT and its nanocomposites obtained from cone calorimeter tests at a heat flux of $50 \mathrm{~kW} \mathrm{~m}^{-2}$. The corresponding data are listed in Table S3. $\dagger$ Neat PBT has high peak SPR (PSPR) and TSP values. The addition of POSS into PBT delays the smoke production time $\left(\Delta t_{\mathrm{PSPR}}=+35 \mathrm{~s}\right)$ due to the rapid swelling and accumulation of POSSs moieties on the surface of the underlying matrix. ${ }^{27}$ The incorporation of F-POSS further delays the smoke production $\left(\Delta t_{\mathrm{PSPR}}=+65 \mathrm{~s}\right)$ and significantly reduces the PSPR value. PBT/F-POSS composite records an approximate $46 \%$ reduction in PSPR. The results indicate that F-POSS can function as effective smoke suppressant due to its ability to capture phosphoric radicals and the phosphorus-nitrogen-silicon ternary synergistic effect. ${ }^{\mathbf{4 2 - 4 4}}$

Smoke density chamber testing can give detailed information about the smoke production. ${ }^{15,48}$ The smoke density value negatively correlates with luminous flux according to ISO 56592. The luminous flux curves of neat PBT and its nanocomposites without flame are exhibited in Fig. 6. The changes in smoke evolution for the three samples are in agreement with SPR and TSP curves obtained from cone calorimeter tests. In the case of neat PBT, the luminous flux rapidly decreases in the first $200 \mathrm{~s}$. The luminous flux value is $19.0 \%$ at $150 \mathrm{~s}$, but reduces to $2.9 \%$ at $200 \mathrm{~s}$, suggesting that lots of smoke are produced in the first 200 s. When POSS is added into PBT, the rate of smoke production is reduced. The luminous flux value of PBT/POSS is $46.9 \%$ at $150 \mathrm{~s}$, but decreases further to $17.9 \%$ at $200 \mathrm{~s}$. The results suggest that the introduction of POSS inhibits smoke production in the initial stage of heat radiation. This phenomenon is attributed to the ceramization process 

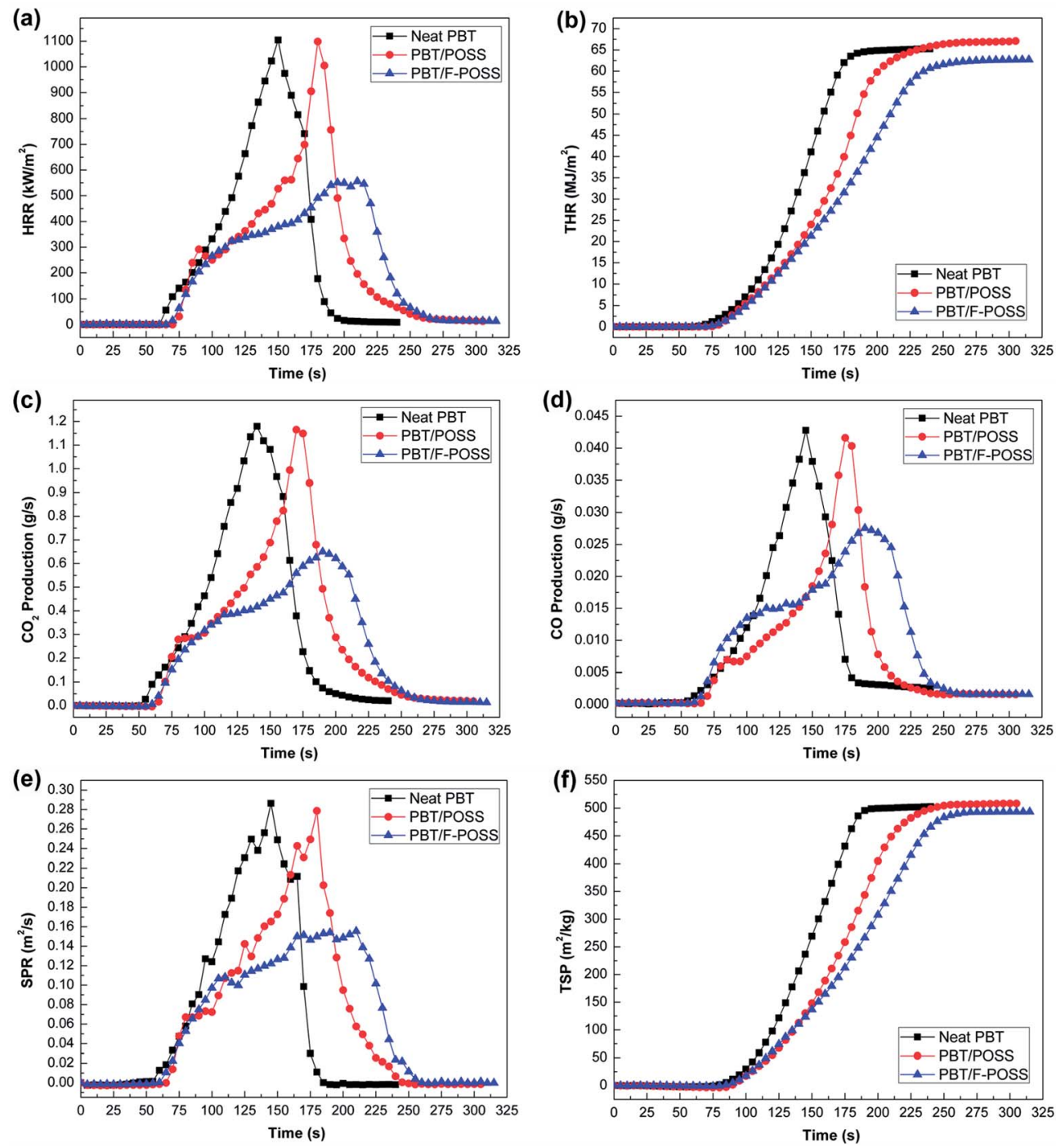

Fig. 5 HRR (a), THR (b), COP (c), $\mathrm{CO}_{2} \mathrm{P}$ (d), SPR (e) and TSP (f) as a function of the burning time of neat PBT, PBT/POSS and PBT/F-POSS in the cone calorimeter testing at $50 \mathrm{~kW} \mathrm{~m}^{-2}$.

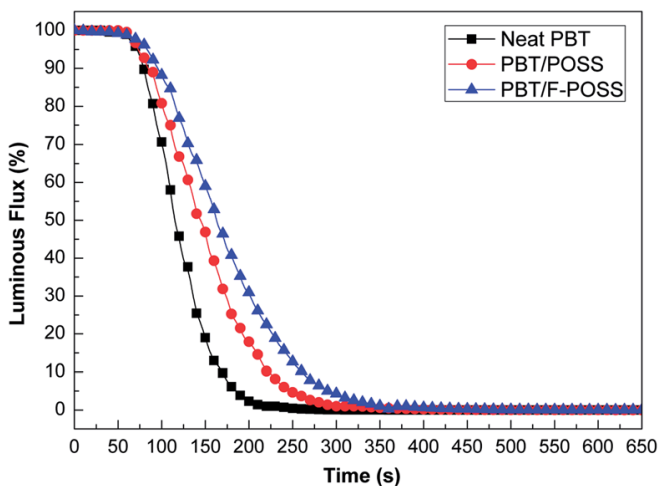

Fig. 6 Luminous flux curves of neat PBT, PBT/POSS and PBT/F-POSS in the smoke density testing at $25 \mathrm{~kW} \mathrm{~m}^{-2}$ without flame.

involving polysilsesquioxanes migration on the surface to retard the thermal radiation and mass transfer. ${ }^{41}$ The incorporation of F-POSS into PBT further reduces the smoke production rate.
Initially, the luminous flux value of PBT/F-POSS is $59.0 \%$ at $150 \mathrm{~s}$, but decreases to $30.9 \%$ at $200 \mathrm{~s}$, indicating that the release of smoke is strongly retarded by the phosphorusnitrogen-silicon ternary synergistic effect in the early stage of thermal radiation. ${ }^{42-44}$ Although the addition of POSS and F-POSS can not reduce the smoke production after $400 \mathrm{~s}$, the inhibited smoke production in the early stage of heat radiation is very important for human escape and rescue.

\section{Flame retardant mechanism}

The improved flame retardant properties of PBT/F-POSS nanocomposites are probably attributed to good carbonization and ceramization effect. From the TGA results, it has been concluded that POSS and F-POSS improve the char formation and inhibit the degradation of PBT. PBT/F-POSS shows more significant carbonization effect, which is in good agreement with its higher residual yield ( $8.2 \mathrm{wt} \%)$ in cone calorimeter testing. Fig. $\mathrm{S} 3 \uparrow$ shows the digital photographs of the residues 
for PBT/POSS and PBT/F-POSS after cone calorimeter tests. It is observed that lots of char yields for the two nanocomposites are left. In order to understand the flame retardant mechanism, the characteristics of these residues were studied by SEM coupled with EDX analyzer. Fig. S4 $\uparrow$ displays the SEM images of the outer residues for PBT/POSS and PBT/F-POSS in low magnification $(\times 200)$. There are many particles distributed on the surface of the two residues. In high magnification SEM images (Fig. 7), it is clearly seen that the size of these particles for PBT/ POSS and PBT/F-POSS are nanoscale, which are interconnected to form a network. The nanoparticle morphology for PBT/FPOSS is more homogeneous than that for PBT/POSS. The EDX results of outer residues for PBT/POSS (Fig. S5 $\dagger$ ) show that the nanoparticles are primarily composed of $\mathrm{C}$, O, and Si elements (element content: $\mathrm{C}>\mathrm{Si}>\mathrm{O}$ ). It indicates that charring reaction occurs in the burning process of PBT/POSS leading to the formation of $\mathrm{SiO}_{x} \mathrm{C}_{y}$ nanoparticles which rapidly migrate to the surface to yield a charred ceramic network leading to the retarded heat release. ${ }^{35,36}$ In the EDX results of outer residues for PBT/F-POSS (Fig. S6 $\dagger$ ), P element is detected (element content: $\mathrm{C}>\mathrm{O}>\mathrm{Si}>\mathrm{P}$ ), and both the contents of $\mathrm{C}$ and $\mathrm{O}$ elements are more than those for PBT/POSS. It illustrates that the phosphinic groups in F-POSS firstly reacts with oxygen to form phosphate derivatives. They capture the free radicals or decomposed products of PBT to produce the stable $\mathrm{SiO}_{x} \mathrm{C}_{y} \mathrm{P}_{z}$ network. Therefore, more $\mathrm{C}$ and $\mathrm{O}$ elements are remained in the carbonization process, which is consistent with the reported study. ${ }^{27}$ The improved $\mathrm{C}$ and $\mathrm{O}$ concentrations greatly contribute to the reduction of $\mathrm{HRR}, \mathrm{CO}_{2}$ and $\mathrm{CO}$ production as well as smoke emission.

The SEM images of inner residues for PBT/POSS are shown in Fig. 8 and S7. $\dagger$ Lots of bubbles are seen in the inner surface of the residues suggesting that the sample expands when it is heated in the cone calorimeter test (Fig. S7†). The expansion is possibly attributed to the decomposition of POSS in which the nonflammable nitrogen oxide gases and silicon oxides are formed and migrate to the burning area. The rapid intumescent effect limits the heat and mass transfer during the initial stage of the burning process for PBT/POSS. ${ }^{27,49}$ Therefore, the $t_{\text {ign }}$ and $t_{\mathrm{p}}$ values are remarkably improved, and the HRR is inhibited in the early stage. The EDX results of the inner residues for PBT/ POSS (Fig. S8†) shows that the inner residues are mainly composed of C, O, and Si elements (element content: $\mathrm{Si}>\mathrm{O}>\mathrm{C}$ ). The extremely low $\mathrm{C}$ element content leads to the formation of unstable ceramified char. It can be easily destroyed by the continuous heat radiation resulting in the increasing HRR as well as $\mathrm{CO}_{2}$, CO, and smoke production. The inner char residues for PBT/F-POSS are different from PBT/POSS. As shown in Fig. 8(c), there are no bubbles in the residues. Many inhomogenous holes are observed. In the high magnification SEM image (×30 000) (Fig. 8(d)), many nanoparticles are distributed on the surface of the inner char. Fig. S9† shows the SEM image of the inner char for PBT/F-POSS in higher magnification $(\times 60000)$. It is clearly seen that the nanoparticles are homogenous with the size of 20-50 nm, which should be silicon-containing oxides. The EDX results of inner residues for PBT/F-POSS (Fig. S10 $\dagger$ ) shows that the inner chars are composed of $\mathrm{C}, \mathrm{O}, \mathrm{Si}$, and $\mathrm{P}$ elements (element content: $\mathrm{C}>\mathrm{Si}>\mathrm{O}>\mathrm{P}$ ). The proportion of $\mathrm{C}$ element is much higher than that for PBT/POSS, indicating the formation of additional char residues in the intumescent process owing to the catalysis carbonization effect of phosphinic groups in F-POSS. Additionally, plenty of nanoparticles are embedded in the inner char layer to form a stable barrier which can effectively reduce the exposure of polymer matrix to an external heat source as well as retard the flammable gases to feed flame. The combined action of carbonization and ceramization contributes to the significant reduction of fire, smoke, and toxicity hazards in PBT/F-POSS nanocomposite.

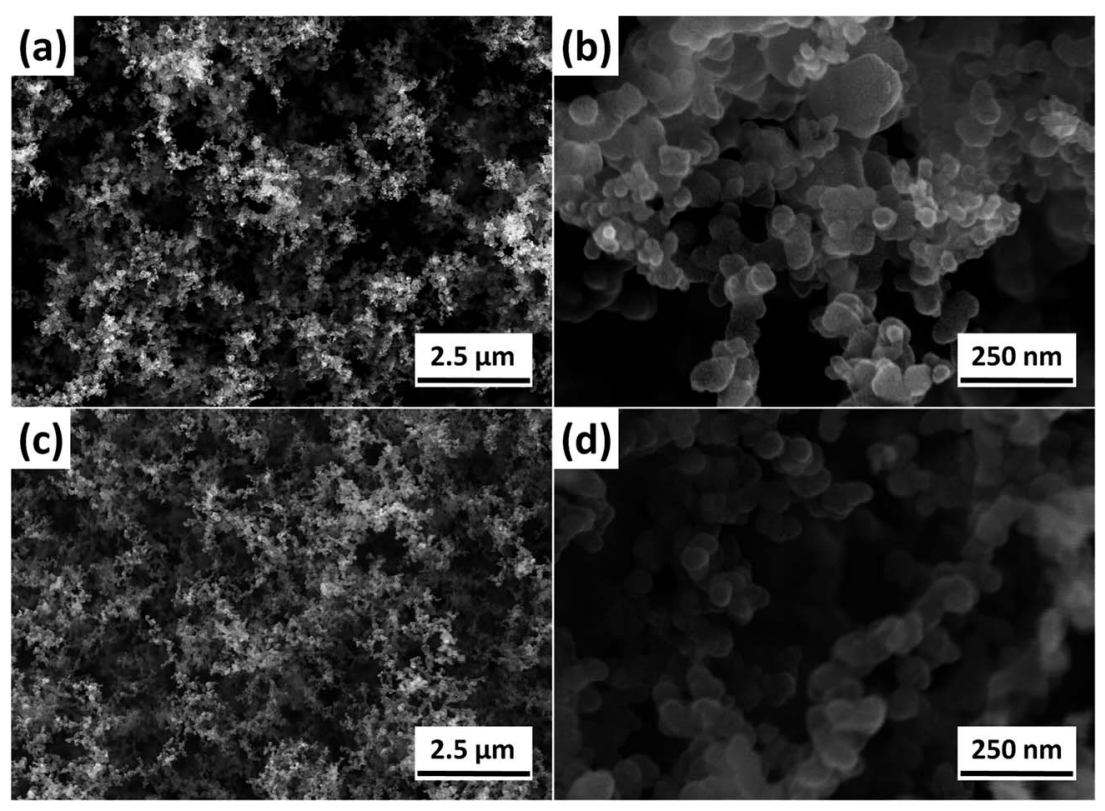

Fig. 7 SEM images of the outer residues after cone calorimeter testing: (a and b) PBT/POSS; (c and d) PBT/F-POSS 


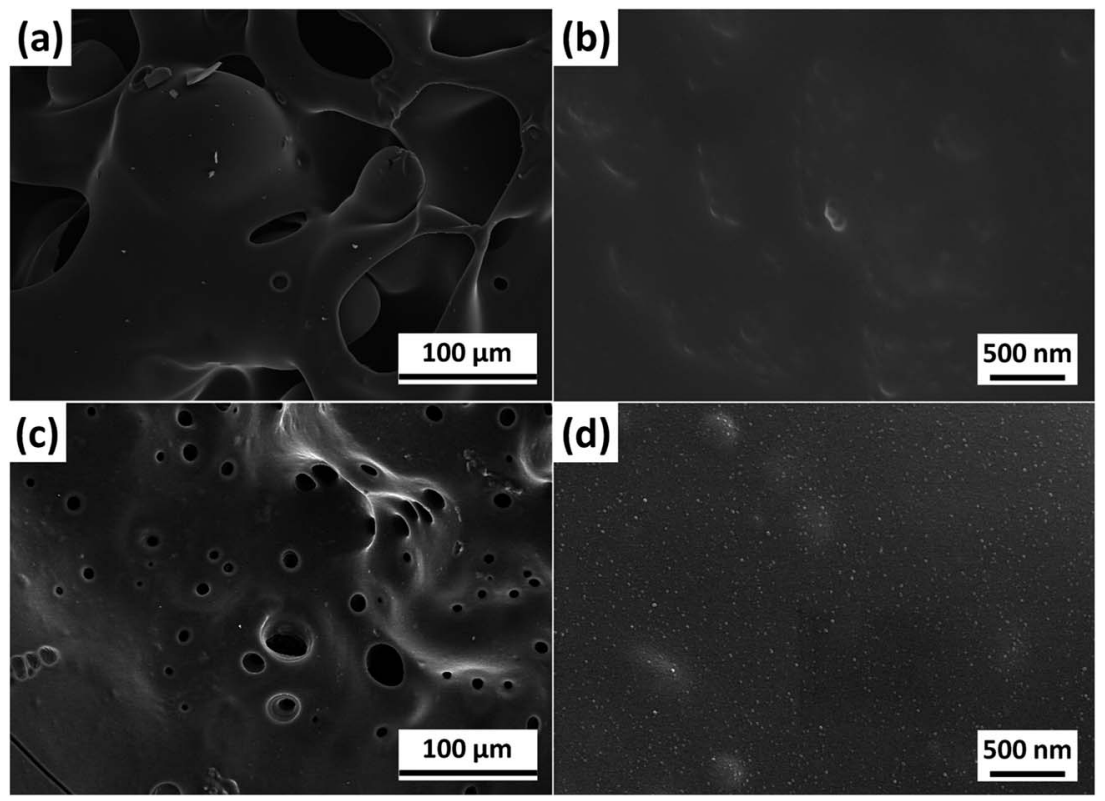

Fig. 8 SEM images of the inner residues after cone calorimeter testing: ( $a$ and b) PBT/POSS; (c and d) PBT/F-POSS.

\section{Conclusions}

In this work, F-POSS containing phosphorus and nitrogen elements was synthesized by the reaction between $N$ phenylaminopropyl-POSS and DPP-Cl. Untreated POSS and FPOSS were respectively mixed with PBT to prepare the nanocomposites via a melt blending method. PBT/F-POSS has superior mechanical properties, thermal stability and thermooxidative resistance in comparison with PBT/POSS. F-POSS exhibits more significant inhibiting effect on the smoke production of PBT in the early heating stage of smoke density chamber testing without flame. Cone calorimeter testing results illustrate that the incorporation of F-POSS to PBT significantly reduces the $\mathrm{PHRR}$, PSPR, $\mathrm{PCO}_{2} \mathrm{P}$ and $\mathrm{PCOP}$. Residue analysis indicates that more $\mathrm{C}$ and $\mathrm{O}$ atoms are remained during the expansion and carbonization process in which phosphinic groups of F-POSS can capture the free radicals or decomposed products of PBT to produce stable $\mathrm{SiO}_{x} \mathrm{C}_{y} \mathrm{P}_{z}$ network. The multiple protective char layers caused by the carbonization and ceramization effects acted as a thermal barrier on the surface of the substrate, limiting heat and mass transfer, leading to the significant reduction of fire, smoke, and toxicity hazards.

\section{Conflicts of interest}

There are no conflicts to declare.

\section{Acknowledgements}

This work was co-financed by National Natural Science Foundation of China (51403048, 21702042, 51606092, and 51276054), Anhui Provincial Natural Science Foundation (1508085QE111 and 1508085QB31), Natural Science Foundation in University of Anhui Province (KJ2016A606 and KJ2015A275), Talent Scientific
Research Foundation of Hefei University (16-17RC07 and 14RC06), Natural Science Projects in Research Development Foundation of Hefei University (16ZR09ZDA), Program for Excellent Young Talents in University of Anhui Province (gxfx2017098), and the Open Project Program of the State Key Laboratory of Fire Science (HZ2016-KF02).

\section{References}

1 G. Mago, F. T. Fisher and D. M. Kalyon, Macromolecules, 2008, 41, 8103.

2 J. F. Xiao, Y. Hu, Z. Z. Wang, Y. Tang, Z. Y. Chen and W. C. Fan, Eur. Polym. J., 2005, 41, 1030.

3 S. V. Levchik and E. D. Weil, Polym. Int., 2005, 54, 11.

4 S. V. Levchik and E. D. Weil, Polym. Adv. Technol., 2004, 15, 691.

5 U. Braun and B. Schartel, Macromol. Mater. Eng., 2008, 293, 206.

6 E. Gallo, U. Braun, B. Schartel, P. Russo and D. Acierno, Polym. Degrad. Stab., 2009, 94, 1245.

7 W. Yang, B. H. Yang, H. D. Lu, L. Song and Y. Hu, Ind. Eng. Chem. Res., 2014, 53, 18489.

8 W. Yang, Y. Hu, Q. L. Tai, H. D. Lu, L. Song and R. K. K. Yuen, Composites, Part A, 2011, 42, 794.

9 W. Yang, R. K. K. Yuen, Y. Hu, H. D. Lu and L. Song, Ind. Eng. Chem. Res., 2011, 50, 11975.

10 S. S. Ray and M. Okamoto, Prog. Polym. Sci., 2003, 28, 1539.

11 T. Kashiwagi, F. Du, J. F. Douglas, K. I. Winey, R. H. Harris and J. R. Shields, Nat. Mater., 2005, 4, 928.

12 W. Y. Xing, W. Yang, W. J. Yang, Q. H. Hu, J. Y. Si, H. D. Lu, B. H. Yang, L. Song, Y. Hu and R. K. K. Yuen, ACS Appl. Mater. Interfaces, 2016, 8, 26266.

13 B. Yu, Y. Shi, B. Yuan, S. Qiu, W. Xing, W. Hu, L. Song, S. Lo and Y. Hu, J. Mater. Chem. A, 2015, 3, 8034. 
14 Y. Shi, B. Yu, L. Duan, Z. Gui, B. Wang, Y. Hu and R. K. Yuen, J. Hazard. Mater., 2017, 332, 87.

15 E. Naderi-Kalali, X. Wang and D. Y. Wang, J. Mater. Chem. A, 2015, 3, 6819.

16 W. C. Zhang, X. M. Li and R. J. Yang, Polym. Degrad. Stab., 2011, 96, 2167.

17 W. Gianelli, G. Camino, D. Tabuani, V. Bortolon, T. Savadori and O. Monticelli, Fire Mater., 2006, 30, 333.

18 W. Yang, Y. C. Kan, L. Song, Y. Hu, H. D. Lu and R. K. K. Yuen, Polym. Adv. Technol., 2011, 22, 2564.

19 D. Wang, Q. Zhang, K. Zhou, W. Yang, Y. Hu and X. Gong, J. Hazard. Mater., 2014, 278, 391.

20 W. C. Zhang, X. M. Li and R. J. Yang, Polym. Degrad. Stab., 2014, 99, 118.

21 T. Pawlak, A. Kowalewska, B. Zgardzinska and M. J. Potrzebowski, J. Phys. Chem. C, 2015, 119, 26575.

22 S. W. Kuo and F. C. Chang, Prog. Polym. Sci., 2011, 36, 1649.

23 S. D. Jiang, G. Tang, Z. M. Bai, Y. Y. Wang, Y. Hu and L. Song, RSC Adv., 2014, 4, 3253.

24 B. H. Yang, H. Y. Xu, Z. Z. Yang and X. Y. Liu, J. Mater. Chem., 2009, 19, 9038.

25 A. L. Goffin, E. Duquesne, J. M. Raquez, H. E. Miltner, X. Ke, M. Alexandre, G. V. Tendeloo, B. V. Mele and P. Dubois, J. Mater. Chem., 2010, 20, 9415.

26 W. C. Zhang, X. M. Li, X. Y. Guo and R. J. Yang, Polym. Degrad. Stab., 2010, 95, 2541.

27 Z. Qi, W. C. Zhang, X. D. He and R. J. Yang, Compos. Sci. Technol., 2016, 127, 8.

28 J. H. Wang, O. Altukhov, C. C. Cheng, F. C. Chang and S. W. Kuo, Soft Matter, 2013, 9, 5196.

29 B. Liang, X. D. Hong, M. Zhu, C. J. Gao, C. S. Wang and N. Tsubaki, Polym. Bull., 2015, 72, 2967.

30 Y. Wang, M. J. Xu and B. Li, Polym. Degrad. Stab., 2016, 131, 20.

31 J. Bardon, K. Apaydin, A. Laachachi, M. Jimenez, T. Fouquet, F. Hilt, S. Bourbigot and D. Ruch, Prog. Org. Coat., 2015, 88, 39.
32 W. H. Xu, A. Wirasaputra, S. M. Liu, Y. C. Yuan and J. Q. Zhao, Polym. Degrad. Stab., 2015, $122,44$.

33 X. Wang, Y. Hu, L. Song, W. Y. Xing, H. D. Lu, P. Lv and G. X. Jie, Polymer, 2010, 51, 2435.

34 T. Mayer-Gall, D. Knittel, J. S. Gutmann and K. Opwis, ACS Appl. Mater. Interfaces, 2015, 7, 9349.

35 R. A. Mantz, P. F. Jones, K. P. Chaffee, J. D. Lichtenhan, J. W. Gilman, I. M. K. Ismail and M. J. Burmeister, Chem. Mater., 1996, 8, 1250.

36 A. Fina, D. Tabuani, F. Carniato, A. Frache, E. Boccaleri and G. Camino, Thermochim. Acta, 2006, 440, 36.

37 V. Pistor, B. G. Soares and R. S. Mauler, Polym. Compos., 2012, 33, 1437.

38 Z. P. Zhang, A. J. Gu, G. Z. Liang, P. G. Ren, J. Q. Xie and X. L. Wang, Polym. Degrad. Stab., 2007, 92, 1986.

39 W. Yang, H. D. Lu, Q. L. Tai, Z. H. Qiao, Y. Hu, L. Song and R. K. K. Yuen, Polym. Adv. Technol., 2011, 22, 2136.

40 G. Botelho, A. Queirós, S. Liberal and P. Gijsman, Polym. Degrad. Stab., 2001, 74, 39.

41 A. Fina, D. Tabuani and G. Camino, Eur. Polym. J., 2010, 46, 14.

42 X. D. Qian, L. Song, B. H. Yuan, B. Yu, Y. Q. Shi, Y. Hu and R. K. K. Yuen, Mater. Chem. Phys., 2014, 143, 1243.

43 F. H. Liao, L. Zhou, Y. Q. Ju, Y. Y. Yang and X. L. Wang, Ind. Eng. Chem. Res., 2014, 53, 10015.

44 Y. Qian, P. Wei, P. K. Jiang, J. W. Hao and J. X. Du, Composites, Part B, 2013, 45, 1541.

45 H. Y. Yang, X. D. Zhou, L. Z. Yang and T. L. Zhang, Materials, 2015, 8, 4210.

46 K. Zhou, W. Yang, G. Tang, B. Wang, S. Jiang, Y. Hu and Z. Gui, RSC Adv., 2013, 3, 25030.

47 K. Zhou, Z. Gui and Y. Hu, Composites, Part A, 2016, 80, 217. 48 X. Chen, Y. Jiang and C. Jiao, J. Hazard. Mater., 2014, 266, 114.

49 S. Bourbigot, T. Turf, S. Bellayer and S. Duquesne, Polym. Degrad. Stab., 2009, 94, 1230. 